\title{
Electronic Photodepletion Spectroscopy of Dibenzo-18-crown-6 with a Potassium Ion
}

\author{
Hwan Jin Kim, Won Jik Shin, Chang Min Choi, Jun Ho Lee, and Nam Joon Kim*
}

\author{
Department of Chemistry, Chtungbuk National University, Chungbuk 361-763. Korea. "E-mail: namjkim(atchungbuk ac.k. \\ Received July: 25, 2008
}

\begin{abstract}
Electronic photodepletion spectrum of dibenzo-18-crown- 6 with a potassium ion ( $\mathrm{K}^{+}$-DBl8C6) was obtained in the gas phase using electrospray ionization and quadrupole ion-trap reflectron time-of-flight mass spectrometry. The spectrum exhibited rather a broad absorption band at $36350 \mathrm{~cm}^{-1}$, which was tentatively assigned as the origin of the $\mathrm{S}_{1}$ band. The photodepletion spectrun of $\mathrm{Cs}^{+}$-DB18C6 was also obtained to elaborate the effects of metal cations on electronic and geonetric structures of metal cation-DB $18 \mathrm{C} 6$ complexes. We found that the $\mathrm{S}_{1}$ band of $\mathrm{Cs}^{-}-\mathrm{DB} 18 \mathrm{C} 6$ was red-shifted by $180 \mathrm{~cm}^{-1}$ fron that of $\mathrm{K}^{+}-\mathrm{DB} 18 \mathrm{C} 6$. With the results of quantum theoretical calculations using the density functional theory, we suggested that the red-shift arose mainly from weaker binding of $\mathrm{Cs}^{+}$to $\mathrm{DB} 18 \mathrm{C} 6$ than that of $\mathrm{K}^{-}$, which resulted from a larger size of $\mathrm{Cs}^{+}$than that of the cavity in DB18C6
\end{abstract}

Key Words : Photodepletion spectrum, Electrospray ionization, Dibenzo-18-crown-6, Quadrupole ion trap

\section{Introduction}

Molecular sensors have strong affinity to specific molecules or ions and in most cases, their physical and chemical properties change significantly upon binding to them. ${ }^{1}$ Crown ethers, first synthesized by Charles Pederson in $1967,0^{2,3}$ are one of the well-known molecular sensors for metal cations. The first crown ethers are 18-crown-6 (18C6) and dibenzo18-crown-6 (DB18C6) (Scheme 1). They were reported to have strong affinity to the metal cations whose radii were similar to their cavity sizes. For example, 18C6 exhibited the strongest binding affinity to a potassium ion $\left(\mathrm{K}^{+}\right)$, the radius of which was the closest to the cavity size among other alkali metal cations. ${ }^{4}$ However, other factors were also known to contribute to the selective binding of crown ethers such as solvation enthalpies and entropies of the cations, the number of donor atoms of a crown ether participating in the binding to a metal cation, and the conformational difference between the bound and unbound crown ethers.

Many derivatives of crown ethers of different binding selectivity have also been synthesized. ${ }^{6}$ Misumi and coworkers $^{7}$ synthesized a crowned di-nitrophenyl-azophenol that changed its color by binding to $\mathrm{Li}^{+}$. Kim and coworkers ${ }^{8}$ reported the synthesis of calix-azacrown-ethers which had the selectivity for $\mathrm{K}^{-}$and changed their colors when they bound with $\mathrm{K}^{+}$. De Silva et al. ${ }^{y}$ also studied crown ethers

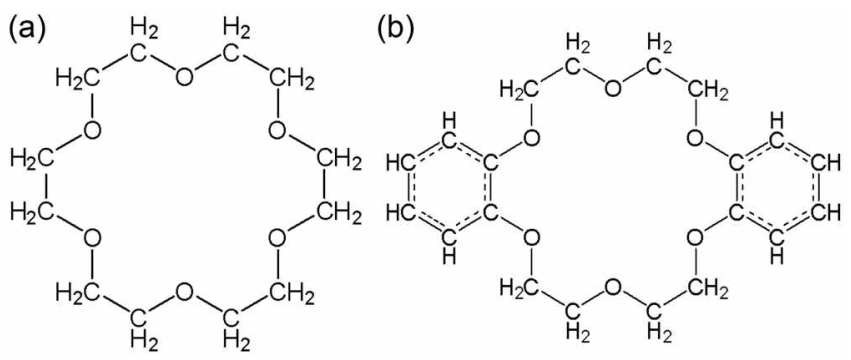

Scheme 1 which emitted fluorescence when they bound with a specific ion. The changes in physical and chemical properties of crown ethers upon complexation with various cations have been investigated using fluorescence spectroscopy or nuclear magnetic resonance spectroscopy. ${ }^{10-11}$

However, most of these studies have been carried out in solution phase, where the interactions with solvents or other species in solution cannot be excluded and may affect the physical and chemical properties of crown-ether complex ions. Therefore, to elucidate the intrinsic nature of crown-ether complex ions, it is critical to investigate them in isolated gas phase.

The advent of an electrospray ionization (ESI) technique combined with mass spectrometry ${ }^{13}$ provides a powerful tool to study the mass-selected crown-ether complex ions in the gas phase. Gas-phase selectivity of crown ethers was investigated using the kinetic method. ${ }^{14}$ They generated ion complexes of crown ethers with two different alkali metal cations and measured relative abundance of their product ions following high-energy dissociation. Intrinsic cation affinities and complexation rates for alkali metal cations of crown ethers were measured following ion-molecule reactions in the gas phase. ${ }^{15}$ Bond-dissociation energies of gasphase crown ether complexes with alkali metal cations were determined from the thresholds of collision-induced dissociation obtained using guided ion beam mass spectrometry. ${ }^{16}$ Recently, Ebata and coworkers ${ }^{17}$ reported the laserinduced fluorescence spectra of jet-cooled benzo-18-crown6, dibenzo-18-crown-6 and their hydrated complexes. However, spectroscopic studies on gas-phase crown ether complexes with alkali metal cations, which may reveal their photo-physical and -chemical properties, have never been performed, as far as we know.

In this paper, we obtained the first electronic photodepletion spectrum of DB18C6 complexes with $\mathrm{K}^{+}$using ESI and quadrupole ion trap reflectron time-of-flight mass spectrometry (QIT-reTOF). DB18C6 was chosen because it has benzene rings as a chromophore for ultraviolet light 
(UV). Moreover, with the proximity of the benzene rings to the cavity of DB18C6, the interactions between DB18C6 and metal cations can be closely monitored by UV absorption spectroscopy of the complex ions

To know how the metal cations of different characters affect geometric and electronic structures of the complex ions, the photodepletion spectrum of $\mathrm{Cs}^{+}-\mathrm{DB} 18 \mathrm{C} 6$ was also obtained and compared with that of $\mathrm{K}^{-}$-DB18C6. The redshift of the first singlet excitation band $\left(\mathrm{S}_{1}\right)$ of $\mathrm{Cs}^{+}-\mathrm{DB} 18 \mathrm{C} 6$ from that of $\mathrm{K}^{+}$-DB18C6 was observed and explained with the results of theoretical calculations performed using the density functional theory (DFT).

\section{Experimental Methods}

The details of our experimental set-up were reported previously $^{18}$ and only a brief description will be given.

The powder samples of DB18C6, KCl, and $\mathrm{CsCl}$ were purchased from Aldrich and used without further purification. Each powder sample was dissolved in methanol at a concentration of $200 \mu \mathrm{M}$. The solution of DB $18 \mathrm{C} 6$ was then mixed with the same volume of the $\mathrm{KCl}$ and $\mathrm{CsCl}$ solution to produce $\mathrm{K}^{+}$- and $\mathrm{Cs}^{+}-\mathrm{DB} 18 \mathrm{C} 6$, respectively. Each of the mixed solutions was electro-sprayed into ion droplets through a nozzle floated to $+3 \mathrm{kV}$. The ion droplets evaporated their solvent molecules while passing through a heated capillary. The desolvated ions entered into the main chamber through a skimmer and then trapped in a QIT. A liquid nitrogen reservoir was placed on top of the QIT to lower the temperature down to $150 \mathrm{~K}$.

After $90 \mathrm{~ms}$ of ion storage, $\mathrm{UV}$ laser pulses $(-2 \mathrm{~mJ} / \mathrm{pulse})$ were irradiated onto the ions in the QIT for photodissociation. Then, a positive $(+1290 \mathrm{~V})$ and a negative $\mathrm{DC}$ pulse $(-340 \mathrm{~V})$ were applied to the entrance and exit endcap of the QIT, respectively, to extract all fragment and parent ions out to the field-free region of reflectron TOFMS for mass analysis. The ions passing through the field-free region were reflected in the reflectron and detected by microchannel plate. The ion signals were processed and stored by a digital storage oscilloscope. The timings of the trapping, the laser firing, and the application of the extraction DC pulses were all synchronized using a digital delay generator.

Fluorescein $5 \mathbf{4 8}$ was used as a dye to generate visible light in the wavelength range of 544-576 nm from a dye laser pumped by the second harmonic of an $\mathrm{Nd}$ :YAG laser. The visible light was converted into UV beams by second harmonic generation with a BBO crystal.

\section{Theoretical Methods}

The structures of $\mathrm{K}^{-}$- and $\mathrm{Cs}^{+}-\mathrm{DB} 18 \mathrm{C} 6$ in the electronic ground state were optimized using DFT at the B3LYP/6$31+\mathrm{G}$ (d) level. LANL2DZ was used as a basis set for $\mathrm{K}$ and Cs. The singlet excitation energies at the optimized structures were predicted using TD-DFT at the same level of theory. All calculations were performed using the GAUSSIAN 03 package. $^{19}$

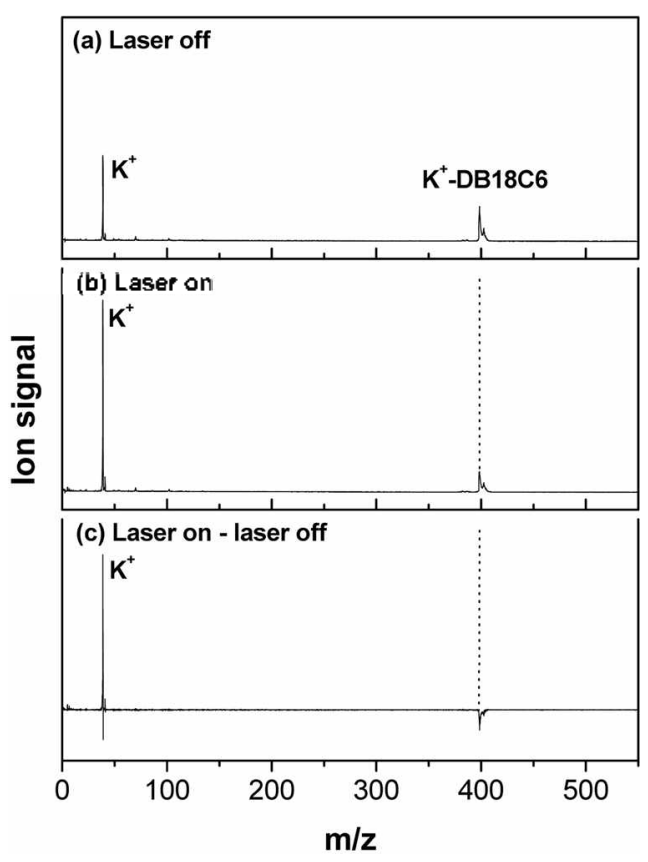

Figure 1. Mass spectra of $\mathrm{K}^{-}-\mathrm{DB} 18 \mathrm{C} 6$ (a) without and (b) with irradiation of laser pulses at $275 \mathrm{~nm}$. (c) Difference mass spectrum obtained by subtracting the laser-off signals from the laser-on.

\section{Results and Discussion}

Figure 1a shows the mass spectrum of $\mathrm{K}^{+}-\mathrm{DB} 18 \mathrm{C} 6$ obtained in the QIT-reTOF. Only the ion signals of $\mathrm{K}^{+}$and $\mathrm{K}^{+}-\mathrm{DB} 18 \mathrm{C} 6$ were observed in the spectrum. One possible source of $\mathrm{K}^{-}$is meta-stable dissociation of $\mathrm{K}^{+}-\mathrm{DB} 18 \mathrm{C} 6$ and the other is unbound $\mathrm{K}^{+}$ions in the $\mathrm{K}^{+}-\mathrm{DB} 18 \mathrm{C} 6$ solution. Figure $1 \mathrm{~b}$ is the mass spectrum obtained with irradiation of laser pulses at $275 \mathrm{~mm}$ onto the ions trapped in the QIT. Figure lc shows the difference spectrum obtained by subtracting the laser-off signals (Fig. la) from the laser-on (Fig. 1b). The negative signal, therefore, represents the intensity of depleted ions and the positive one shows the fragment-ion intensity generated by photo-induced dissociation (PD).

The difference spectrum indicates that $\mathrm{K}^{-}-\mathrm{DB} 18 \mathrm{C} 6$ dissociates to produce $\mathrm{K}^{+}$following absorption of laser pulses at $275 \mathrm{~nm}$. This was also true at other wavelengths where $\mathrm{K}^{+}$-DB18C6 has the absorption. The larger ion signal of the fragment $\mathrm{K}^{+}$than that of the depleted $\mathrm{K}^{-}$-DB18C 6 was attributed to mass-dependent ion trapping and detection efficiency of QIT-reTOF.

Figure 2a shows the electronic photodepletion spectrum of $\mathrm{K}^{-}$-DB18C6 in the wavenumber region of $34900-36810$ $\mathrm{cm}^{-1}$. The spectrum was calibrated against the variation of laser fluence over the frequency. It is likely that the excitation-energy dependence of the photodepletion yield results mainly from the energy dependence of molecular absorption probability. ${ }^{20}$ Therefore, we assumed that the photodepletion spectra exhibited the same spectral feature as the electronic absorption spectra. ${ }^{21,22}$ The photodepletion spectrum of $\mathrm{K}^{-}$-DB $18 \mathrm{C} 6$ showed rather a broad absorption band at $36350 \mathrm{~cm}^{-1}$. Since no other bands appeared at longer 


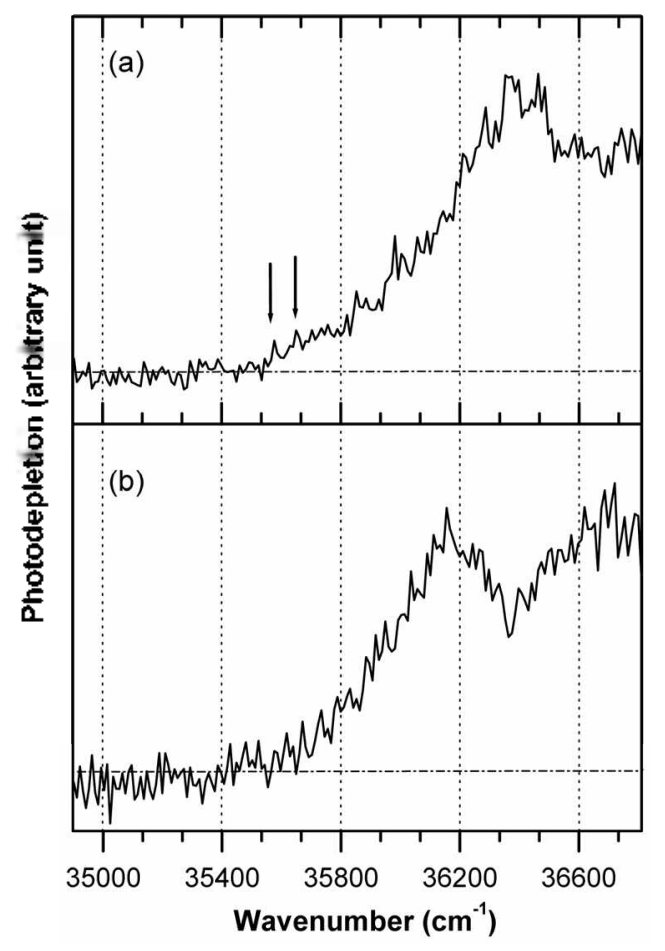

Figure 2. Electronic photodepletion spectra of DBI8C 6 complex ions with (a) $\mathrm{K}^{-}$and (b) $\mathrm{Cs}^{-}$. The arrows indicate the $0-0$ bands of two different conformers of bare DB18C6 (ref. 17). The base lines were represented with a dash-dot line.

wavelength region, we tentatively assigned it as the origin of the first singlet excitation band $\left(\mathrm{S}_{1}\right)$.

The spectrum of $\mathrm{Cs}^{-}-\mathrm{DB} 18 \mathrm{C} 6$ (Fig. 2b) was also obtained to know how the nature of the metal cation bound to DB18C6 affects the spectral feature of the complex ions. Different from the spectrum of $\mathrm{K}^{-}-\mathrm{DB} 18 \mathrm{C} 6$, that of $\mathrm{Cs}^{+}$DB18C6 exhibited two absorption bands in the same wavelength region. The lowest-energy band was at 36170 $\mathrm{cm}^{-1}$ and the two bands were $-500 \mathrm{~cm}^{-1}$ apart. As the previous assignment, ${ }^{11}$ we assigned the second band as a vibronic band revealing the vibrational structure of the $S_{1}$ state. It is noteworthy that the first absorption band of $\mathrm{Cs}^{+}-$ DB18C6 is red-shifted by $180 \mathrm{~cm}^{-1}$ from that of $\mathrm{K}^{-}-\mathrm{DB} 18 \mathrm{C} 6$. The red-shift has not drawn much attention because it is not clearly observable in the solution-phase spectra.

In order to know the cause of the red-shift, quantum theoretical calculations were carried out using DFT at the B3LYP $/ 6-31+G(d)$ level. Figure 3 shows the optimized structures of $\mathrm{K}^{-}$- and $\mathrm{Cs}^{+}-\mathrm{DB} 18 \mathrm{C} 6$ in the electronic ground state, which agree well with previous reports. ${ }^{23.24}$ The lowest excitation energy of $\mathrm{K}^{-}-$or $\mathrm{Cs}^{+}-\mathrm{DB} 18 \mathrm{C} 6$ at the optimized geometry was predicted by TD-DFT at the same level of theory and plotted in Figure 4. It is remarkable that the redshift of the $S_{1}$ band of $\mathrm{Cs}^{-}-\mathrm{DB} 18 \mathrm{C} 6$ from that of $\mathrm{K}^{+}$$\mathrm{DB} 18 \mathrm{C} 6$ is also predicted in the theoretical calculations.

Those experimental and theoretical results show that the metal cations bound in the cavity of DB18C6 play critical roles in determining stable geometries of the complex ions and thereby affect their electronic structures as well. The

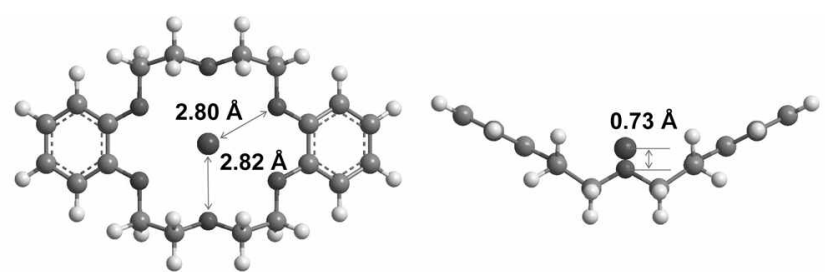

(a) $\mathrm{K}^{+}-\mathrm{DB} 18 \mathrm{C} 6$

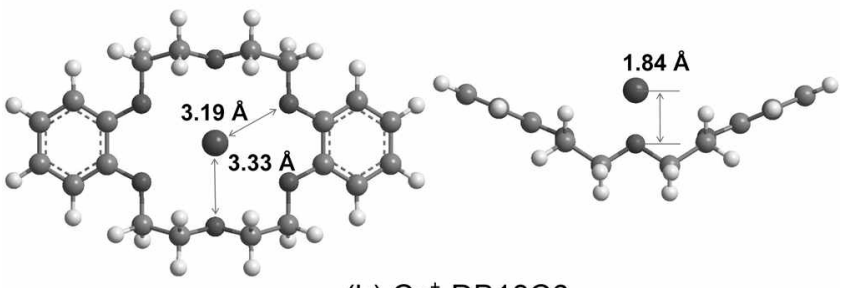

(b) $\mathrm{Cs}^{+}-\mathrm{DB} 18 \mathrm{C} 6$

Figure 3. Optimized structures of DB $18 \mathrm{C} 6$ complexes with (a) $\mathrm{K}^{-}$ and (b) $\mathrm{Cs}^{-}$in the electronic ground state obtained using DFT at the B3LYP $6-31+G(d)$ level.

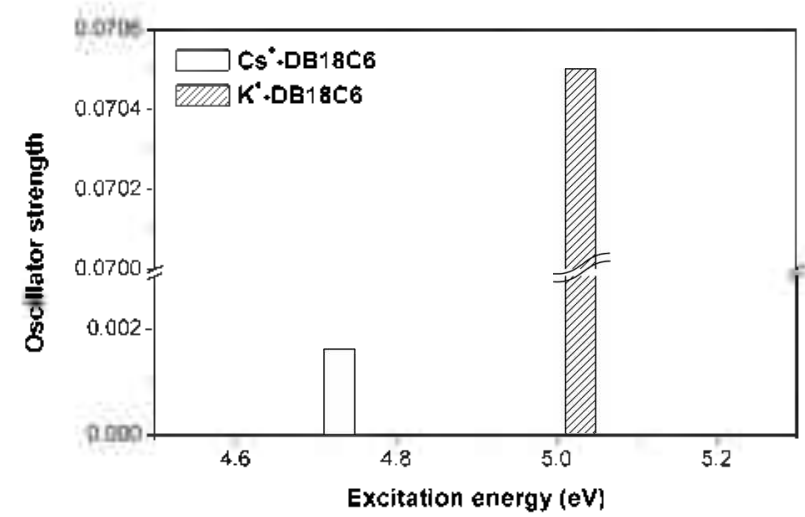

Figure 4. Plot of the singlet excitation energies $\left(\mathrm{S}_{1}\right)$ of $\mathrm{K}^{-}$- and $\mathrm{Cs}^{-}$DB 18 C 6 calculated using TD-DFT at the B3LYP $6-31+\mathrm{G}(\mathrm{d})$ level.

variation of the energies of the first absorption bands indicates the change in relative energies of HOMO (highest occupied molecular orbital) and LLMO (lowest unoccupied molecular orbital). Since the $\mathrm{S}_{1}$ bands of $\mathrm{K}^{-}$- and $\mathrm{Cs}^{-}$DB18C 6 arise from the $\pi \pi^{*}$ transition involving electrons in the $\pi$ and $\pi^{*}$ orbitals of the benzene rings in DB $18 \mathrm{C} 6$, the relative energies of the $\pi$ and $\pi^{*}$ orbitals determine the energies of the $\mathrm{S}_{1}$ bands.

Therefore, we can explain the reason for the red-shift as follows. The cavity radius of DB18C 6 is not known, but the radius of $18 \mathrm{C} 6$, which is about the same as that of $\mathrm{DB} 18 \mathrm{C} 6$, is $1.34-1.43 \AA^{25}$ This is very close to the ionic radius of $\mathrm{K}^{-}$ $(1.38 \AA)$, but much smaller than that of $\mathrm{Cs}^{+}(1.67 \AA)^{26.27}$ Accordingly, in the optimized geometries, $\mathrm{Cs}^{+}$is located at $1.84 \AA$ above the cavity plane made of the six oxygen atoms, while $\mathrm{K}^{-}$sits almost inside the cavity (Fig. 3). In those structures, the distances from the six oxygen atoms to $\mathrm{Cs}^{-}$ are much longer than those to $\mathrm{K}^{+}$. Since the metal cations are practically bound to the six oxygen atoms acting as electron donors in the complex ions, the lengthening of the distance will cause weaker binding of $\mathrm{Cs}^{-}$to $\mathrm{DB} 18 \mathrm{C} 6$ than that of $\mathrm{K}^{+}{ }^{24}$ Therefore, the stabilization of the $\pi$ orbital is expected 


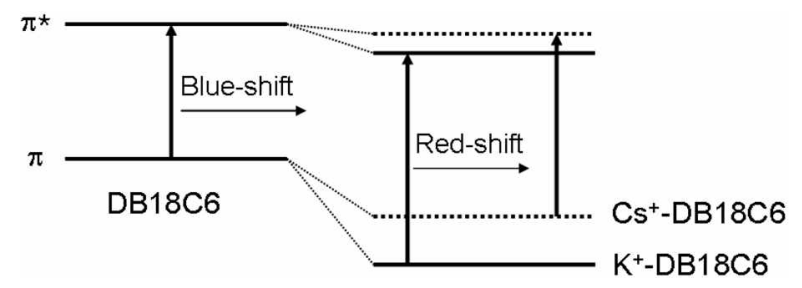

Figure 5. Schematic energy diagram illustrating the red-shift of the $\mathrm{S}_{1}$ band of $\mathrm{Cs}^{-}-\mathrm{DB} 18 \mathrm{C} 6$ from that of $\mathrm{K}^{-}-\mathrm{DB} 18 \mathrm{C} 6$.

to be less upon forming the DB18C6 complex ions with $\mathrm{Cs}^{+}$ than that with $\mathrm{K}^{-}$.

Since the excitation energy to the $S_{1}$ band is determined by the relative energy of both $\pi$ and $\pi^{*}$ orbital, we need to know how the energy of the $\pi^{*}$ orbital as well as that of the $\pi$ orbital changes upon complexation with the metal cations. However, considering that the $\mathrm{S}_{1}$ bands of both $\mathrm{K}^{-}$- and $\mathrm{Cs}^{+}$DB $18 C 6$ are blue-shifted from the $0-0$ band of bare DB18C6 (Fig. 2), ${ }^{17}$ we may insist that the stabilization of the $\pi^{*}$ orbital upon forming the complex ions is less than that of the $\pi$ orbital. This is further supported by the pictorial representations of the $\pi$ and $\pi^{*}$ orbitals (not shown here), which show that the orbitals of the four oxygen atoms near the benzene rings become smaller in the $\pi^{t}$ than in the $\pi$ orbital. Thus, with the reduced strength of the interactions between the $\pi^{*}$ orbitals and the metal cations, the difference in energies of the $\pi^{*}$ orbitals between $\mathrm{K}^{-}$and $\mathrm{Cs}^{+}$-DB18C 6 will be smaller than that of the $\pi$ orbital. Therefore, we suggest that a larger difference in energies of the $\pi$ orbitals between $\mathrm{K}^{+}$- and $\mathrm{Cs}^{-}-\mathrm{DB} 18 \mathrm{C} 6$ compared to that of the $\pi^{*}$ orbitals and also weaker binding of $\mathrm{Cs}^{+}$to DB18C6, leading to less stabilization of both the $\pi$ and $\pi^{*}$ orbitals than that of $\mathrm{K}^{-}$, result in a smaller energy gap between the $\pi$ and $\pi^{*}$ orbitals of $\mathrm{Cs}^{+}-\mathrm{DB} 18 \mathrm{C} 6$ than that of $\mathrm{K}^{-}-\mathrm{DB} 18 \mathrm{C} 6$ (Fig. 5).

\section{Conclusions}

Electronic photodepletion spectra of $\mathrm{K}^{+}$- and $\mathrm{Cs}^{+}$-DB18C6 were obtained in isolated gas phase and investigated with the help of theoretical calculations using DFT and TD-DFT. The red-shift of the $S_{1}$ band was observed upon changing the metal cation bound to DB $18 \mathrm{C} 6$ from $\mathrm{K}^{+}$to $\mathrm{Cs}^{-}$. We suggest that the relative size of metal cations with respect to the cavity size plays a critical role in determining the stable geometries of the complex ions and thereby affects their electronic structures. With a larger size of $\mathrm{Cs}^{+}$than that of the cavity, $\mathrm{Cs}^{-}$sits far above the cavity. In contrast, $\mathrm{K}^{-}$fits inside the cavity with its almost identical radius to that of the cavity. Those structures result in weaker binding of $\mathrm{Cs}^{+}$than that of $\mathrm{K}^{-}$toward $\mathrm{DB} 18 \mathrm{C} 6$, which is mainly responsible for the red-shift of the $\mathrm{S}_{1}$ band of $\mathrm{Cs}^{+}$-DB18C 6 from that of $\mathrm{K}^{+}$DB18C6. The studies of DB18C6 complexes with other alkali and alkaline earth metal cations are under way to investigate the host-guest interactions in more detail using metal cation-DB18C 6 complexes as a model system.

Acknowledgments. This work was supported by the research grant of Chungbuk National University in 2007.

\section{References}

1. Cerrie, W; Rogers, W. O.; Michael, W. O. Coord Chem. Rev 2002, 233, 341

2. Pedersen, C. I. J. Am. Chem. Soc. 1967,89, 7017

3. Pedersen, C. J. Science 1988, 241, 536 .

4. Gokel, G. W.; Leevy, W. M.; Weber, M. E. Chem. Rev 2004, 104 , 2723.

5. Gokel, G W.; Goli, D. M.; Minganti, C.; Echegoyen, L. I. Am. Chen. Soc. 1983, 105, 6786 .

6. Kim, J.-K.; Seo, J. J.; Yim, E. S.; Jin, Y.; Song, S.; Suh, H. Bull. Kor: Chem. Soc. 2008, 29, 1069.

7. Nakashima, K.; Nakatsuii, S.; Akiyama, S.; Kaneda, T.; Misumi, S. Chem. Lett 1982, 11,1781 .

8. Kim, J. S.; Shon, O. J.; Ko, I. W.; Cho, M. H.; Yu, I. Y.; Vicens, I. J. Org. Chem. 2000, 65, 2386.

9. De Silva, A. P.; Gunaratne, H. Q. N.; Gunnlaugsson, T.; Huxley, A. J. M.; McCoy, C. P; Rademacher, J. T.; Rice, T. E. Chem. Rev $1997,97,1515$.

10. Christensen, J. J.; Eatough, D. J.; lzatt, R. M. Chem. Rev. 1974, 74,351 .

11. Shizuka, H.; Takada, K.; Morita, T. J. Phns. Chen 1980, 84, 994.

12. Wilson, M. J.; Pethrick, R. A.; Pugh, D.; lslam, M. S. J. Chem. Soc. Faradar Trans. 1997, 93, 2097.

13. Yamashita, .M.; Femn, J. B. J. Phis. Chem 1984, 88, 4451.

14. Maleknia, S.; Brodbelt, J. J. An. Chent Soc. 1992, 114, 4295.

15. Chu, I.-H.; Zhang, H.; Dearden, D. V. I. Am. Chem. Soc. 1993, 115,5736 .

16. More, M. B.; Ray, D.; Ammentrout, P. B. J. Am. Chem. Soc. 1999 , $121,417$.

17. Kusaka, R.; Inokuchi, Y; Ebata, T. Phis. Chem. Chem. Phis. $2007,9,4452$.

18. Yoon, T. O.; Choi, C. M.; Kim, H. J.; Kim, N. J. Bull. Korean Chen. Soc. 2007, 28, 619 .

19. Frisch, M. J.; Trucks, G. W.; Schlegel, H. B.; Scuseria, G. E; Robb, M. A.; Cheeseman, J. R.; Montgomery, J. A. Jr.; Vreven, T.; Kudin, K. N.; Burant, J. C.; Millam, J. M.; Iyengar, S. S.; Tomasi, I.; Barone, V.; Menuucci, B.; Cossi, M.; Scalmani, G.; Rega, N.; Petersson, G. A.; Nakatsuji, H.; Hada, M.; Ehara, M.; Toyota, K.; Fukuda, R.; Hasegawa, J.; Ishida, M.; Nakajima, T.; Honda, Y.; Kitao, O.; Nakai, H.; Klene, M.; Li, X.; Knox, J. E.; Hratclian, H. P.; Cross, J. B.; Adamo, C.; Jaranillo, J.; Gomperts, R.; Stratmaun, R. E.; Yazyev, O.; Austin, A. J.; Cammi, R.; Pomelli, C.; Ochterski, J. W; Ayala, P. Y; Morokuna, K.; Voth, G A.; Salvador, P.; Dannenberg, J. J.; Zakrzewski, V. G; Dapprich, S.; Daniels, A. D.; Strain, M. C.; Farkas, O.; Malick, D. K.; Rabuck, A. D.; Raghavachari, K.; Foresman, J. B.; Ortiz J. V; Cui, Q.; Baboul, A. G; Clifford, S.: Cioslowski, J.: Stefanov, B. B.; Liu, G; Liaslienko, A.; Piskorz, P.; Kontromi, 1; Martin, R L.; Fox, D. J.; Keith, T.; Al-Lalham, M. A.; Peng, C. Y.; Nanayakkara, A.; Challacombe, M.; Gill, P. M. W; Johnson, B.; Chen, W; Wong, M. W; Gonzalez, C.; Pople, J. A. Gatksian 03, Revision C.02; Gaussian, Inc: Wallingford, CT, 2004.

20. Boyarkin, O. V.; Mercier, S. R.; Kamariotis, A.; Rizzo, T. R. $J$. Am. Chem. Soc. 2006, 128, 2816.

21. Ohashi, K.; Nishi, N. J. Phus Chen. 1992, 96, 2931.

22. Takasu, R; Nishikawa, K.; Miura, N.; Sabu, A.; Hashimoto, K.; Schulz, C. P.; Hertel, I. V; Fuke, K. J. Ph1s, Chem. A 2001, 105 , 6602 .

23. Grootenlhuis, P. D. J.; Kollman, P. A. J. Am. Chem. Soc 1989, 11 , 2152.

24. Anderson, J. D.; Paulsen, E. S.; Dearden, D. V. Int J. Mass Spectron. 2003, 227,63.

25. Dalley, N. K.; Izatt, R. M.; Christensen, J. I. Sinthetic Multidentate Macroclelic Compounds; Academic: New York, 1978.

26. Shannon, R. D. Acta Cristallogr: 1976, A32,751.

27. Jia, Y. Q. J. Solid State Chem. 1991, 95, 184 